\title{
Investigation of the Dithiolene Ligand Conformation in Analogous U(IV)/U(V) Complexes: X-Ray Diffraction and Density Functional Theory Analysis of the $\mathrm{U} \cdots(\mathrm{C}=\mathrm{C})$ Interaction
}

Lotfi Belkhiri, ${ }^{\dagger}$ Thérèse Arliguie, ${ }^{*}{ }^{\ddagger}$ Pierre Thuéry, ${ }^{*}$ Marc Fourmigué," Abdou Boucekkine,, ,I and Michel Ephritikhine

\section{Supplementary Material}

Mean experimental and calculated bond lengths $(\AA)$ and angles $(\mathrm{deg})$ in the $[\mathrm{U}(\mathrm{COT})(\mathrm{dddt})]^{-}$ ${ }^{2,-1,0}$ complexes.

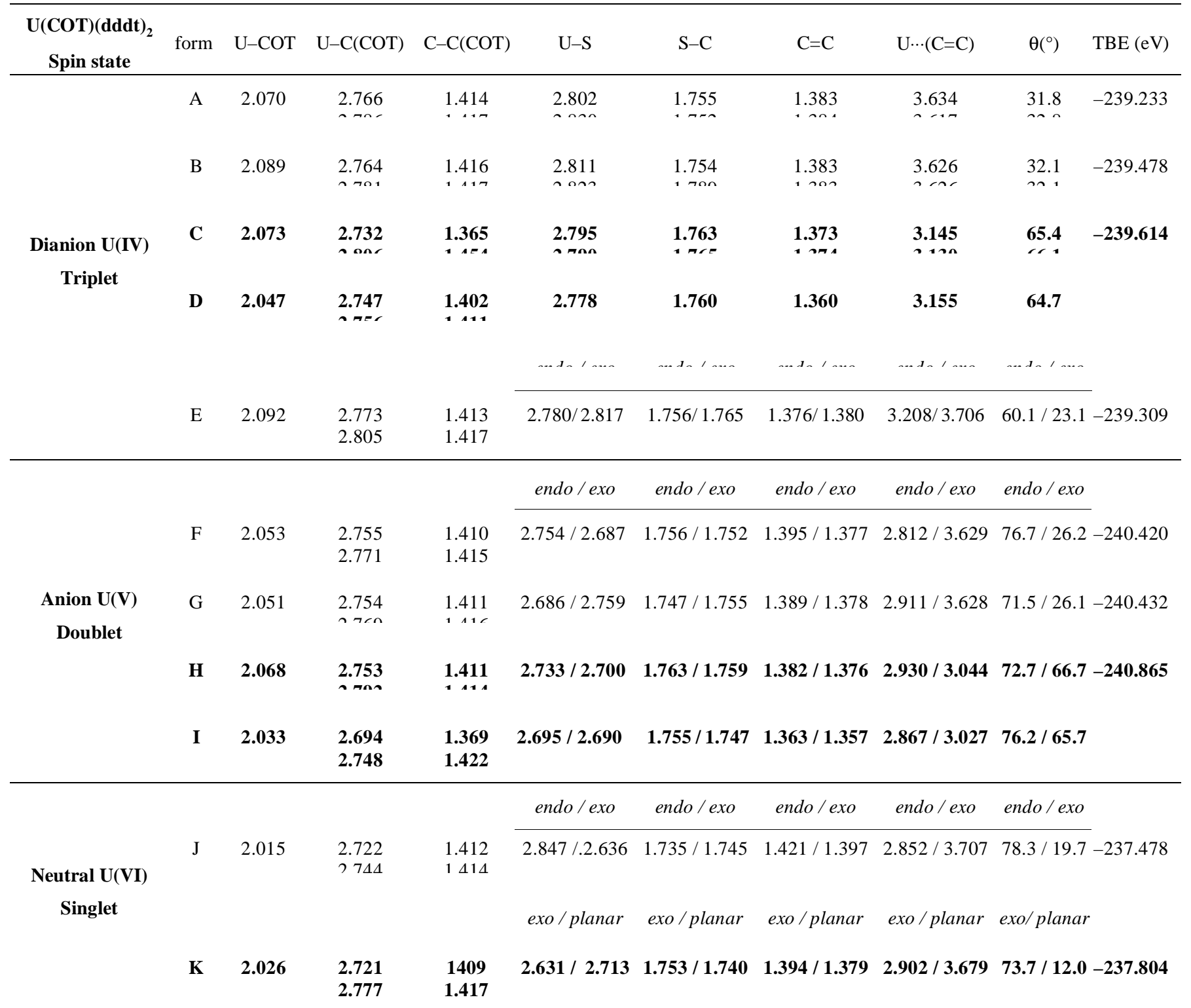

